\title{
Study of Experimental Hysteresis Loops Under Non-Proportional Loading
}

\author{
Nimali T. Medagedara
}

\begin{abstract}
Fatigue life prediction is a challenge for engineers when it comes under nonproportional loading. In many applications, engineering components are subjected to complicated states of stress and strain. Studying of hysteresis behavior under non proportional loading is important for reliable engineering designing for studying the cyclic deformation that is essential to find the plastic strain ranges which is used for fatigue life prediction. This paper discusses the behavior of the hysteresis loops created experimentally under various non-proportional loadings. EN8 carbon steel notched specimen was used for the experimental analysis. The tests were carried out using a multi axial test machine However, the results have shown significant difference in hysteresis behavior changing the path of non-proportional loading. Comparing the experimental results of direct and shear strains of non-proportional loading paths, some loading cycles are more damaging in terms of fatigue life.
\end{abstract}

Keywords: Multiaxial fatigue, Non-Proportional loading, Finite Element Analysis (FEA)

\section{Introduction}

Complex engineering designs subjected to cyclic non proportional loadings help to produce multi axial stresses and these stresses cause to damage the design under multiaxial fatigue. This cyclic load tends to initiate fatigue cracks at notches and at other regions of high stress concentrations. However, fatigue is a problem that occurs in almost every engineering component and most failures are directly related to fatigue [12].

Fatigue is produced by the repeated application of cyclic loading. The first methods for understanding and assessing fatigue in the 1870's used the relationship between the magnitude of nominal stress cycles and the number of cycles to failure [1]. This is the S-N method and it still has applications for components that are designed to survive very large numbers of cycles such as engine connecting rods.

Fatigue testing is recognized as one of the most critical, time consuming and costly activities in product development. Many engineering components are subjected to multiaxial variable amplitude loads that vary either proportionally or non-proportionally. Therefore, accurate fatigue life assessment is an essential requirement in the durability prediction of real design components. Therefore, knowledge of cyclic deformation is essential to find the plastic strain ranges, which is used for fatigue life prediction.
There are a number of software tools to assist design engineers where conceptual designs can be fatigue analysed at the design stage. However, the stress-strain prediction procedure and the accuracy of the life prediction of current software tools have not been verified for a wide range of multiaxial loading cases.

This paper discusses the various types of hysteresis loops that are essential to find the plastic strain ranges which are used for fatigue life prediction under variable amplitude tensiontorsion multiaxial axial proportional and nonproportional paths. The hysteresis loops were obtained for different load sets of proportional and non-proportional loads and the notch root strains were detected experimentally.

\section{Literature Review}

Fatigue has been the cause of many engineering problems since the earliest of components were manufactured. It manifests itself by the initiation of cracks, which may cause a sudden catastrophic failure of the component. However, there are cases where the crack may be allowed to exist or be controlled.

Eng. (Mrs.) T.M.D.N.T. Medagedara, C.Eng., MIE(SL),

MIEEE, B.Sc. Eng.(Hons) (Peradeniya), MPhil. (SHU),

Senior Lecturer in Department of Mechanical Engineering,

The Open University of Sri Lanka.

Email:tmmed@ou.ac.lk

(iD https://orcid.org/0000-0002-7210-0874 
Metal fatigue may cause premature damage or indeed failure in a component subjected to repeated loading. The source of the failure will usually be attributed to a defect in the component material, which when subjected to stress fluctuations will gradually propagate until failure occurs. Often, fatigue failure takes place when components are subjected to nominal cyclic stresses well below their tensile strength [1-2].

Fatigue analysis techniques, whether based on the conventional stress life parameter or the more recent strain-life parameter, are based on the premise that fatigue damage can be accounted for by a single stress or strain variable without regard to the simultaneous presence of other stresses and strains. Essentially the stressstrain field is regarded as uniaxial. Such an assumption simplifies the calculation procedure and may give answers of sufficient accuracy under loading conditions, which are predominantly uniaxial. However, such an assumption cannot be made about many components, which undergo complex multiaxial loading. A method is therefore required which takes into account the interaction between coexisting stresses and strains [3].

Fatigue analysis has become a widely accepted engineering tool and, with the introduction of computers, the use of the technique for the design and development of components has become increasingly more widespread [4].

The modern approach of the fatigue life prediction under uniaxial loading is based on strain rather than stress, the former being more appropriate for modelling the plasticity which the component undergoes at the critical state of failure [5].

The limitations of a computer-based method include the fact that predictions are to the onset of crack initiation and hence it cannot be applied in situations where significant cracks are already present. Under these situations the rate of crack growth governs the fatigue life [6].

The crack may propagate under the application of cyclic loading in any of three modes (Crack Opening Mode, In-plane Shear Mode and Outof-plane Shear Mode) each of which is characterized by a different crack growth function [7]. Currently there are three major approaches to estimate fatigue life, namely, the stress life approach, the strain life approach and the fracture mechanics approach [8].

Generally in high-cycle fatigue (HCF), the stressbased approach is used for designing complex structures where the applied stress is initially within the elastic range of the selected materials. However, the strain-based approach is more appropriate for low-cycle fatigue (LCF) applications where the massive plastic strains exist. Therefore, to study the cyclic deformation that is essential to find the plastic strain range which is used for fatigue life prediction [8-21]. Therefore, fatigue studies depend on prototypes being available to provide a service load history [9]. The strain life approach frequently makes use of Neuber's rule to compute the local (notch) stresses and strains [10-12].

There is no universally accepted life cycle prediction method under multiaxial loading. However, acceptable correlations of multiaxial fatigue data have been obtained using critical plane approaches [13-14].

Since multiaxial stress fields can result from some particular design feature, it may include the presence and shape of notches on the component [12]. Under multiaxial loading conditions fatigue endurance is governed by the maximum shear strain and the tensile strain normal to the plane of maximum shear [15-20]. For multiaxial fatigue it is a strain-based method, strain being judged to be a more appropriate parameter than stress when dealing with plastic deformation [7]. The overall fatigue life under general multiaxial condition is inevitably dictated by the complex phase relations between the different modes of loading [14]. Recently developed approaches for multiaxial fatigue life estimation require both stress and strain behaviour at the notch root as input [18]. The maximum shearing stress theory of fatigue failure and the distortion energy multiaxial theory of fatigue failure are basically extensions of the Tresca and von Mises theories, to detect the fatigue failure. But the experimental evidence has shown that these methods are very conservative [19]. 


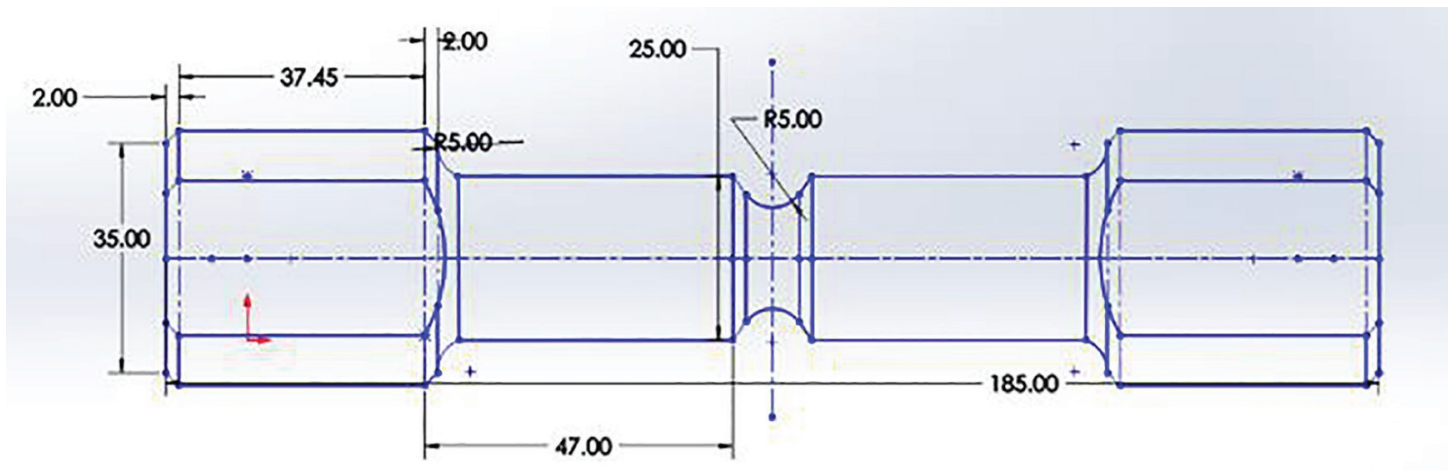

Figure 1 - Dimension of the Specimen

\section{Methodology}

Various in-phase, out of phase and selected nonproportional loadings were applied to a notched specimen made of EN8 carbon steel material (Table 1) and the results of strain at the notch were recorded. Hysteresis loops obtained from the experimental set up were compared for each proportional and predetermined nonproportional loading paths. The complete test procedure can be divided into four main parts which are loading system, control system, torque and strain measuring system and wave generating system.

\subsection{Design of the Specimen}

This study mainly concerns about the failure of the stress strain behaviour at the notch. To get the maximum plasticity at the concern area, diameter at the notch should be larger. The maximum allowable notch diameter was calculated as $15.4 \mathrm{~mm}$. Considering the failures of the bolts, collate and the load ring of the equipment, the maximum allowable notch diameter was calculated as $15 \mathrm{~mm}$ and the other dimensions were selected according to the requirements of the equipment (Figure 1).

Table 1 - Mechanical Properties of the Medium Carbon Steel

\begin{tabular}{|c|c|}
\hline$E$-Young's Modulus & $208 \mathrm{GPa}$ \\
\hline G-Modulus of Rigidity & $80 \mathrm{GPa}$ \\
\hline$v$ - Poisson's Ratio & 0.3 \\
\hline$\sigma_{y}$ - Yield or $0.2 \%$ Proof strength & $320 \mathrm{MPa}$ \\
\hline$\sigma_{u}$ - Ultimate tensile strength & $730 \mathrm{MPa}$ \\
\hline
\end{tabular}

\section{Experimental setup}

\subsection{Multiaxial Loading Machine}

The test had been carried out using a biaxial closed-loop ESH servo-hydraulic test machine that comprises four actuators, two positioned in the vertical axis and two in the horizontal axis with an electronic control system. The movement of all the actuators are purely axial centred on the $x$ and $y$ planes. Pictorial views of the machine are shown in Figures 2 and 4.

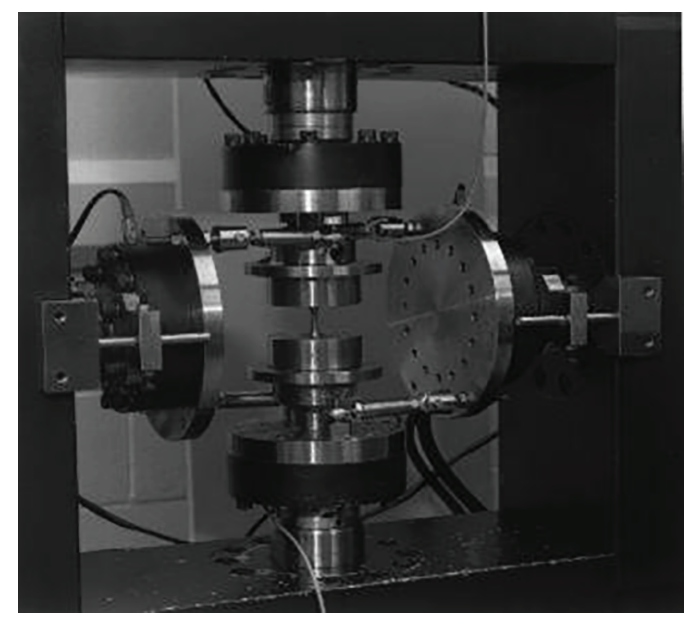

Figure 2 - Specimen Housing for Torsion and Axial Cyclic Loading

This specimen housing consisted of four plates. Two of them were connected to the upper and lower load cells to apply push-pull loads; and the other two worked as torque plates on the right and left hand sides of the specimen. Torque was imposed by the torque pins connected to the torque plates. The specimen was connected to the loading rings by clutches, and load rings were connected to the upper and lower plates The actuators are controlled by the electronic control panel. 


\subsection{Experimental Procedure}

The specimen was fixed to the ESH machine and subjected to tension-torsion load under different loading paths. Three strains and torques were measured by using three amplifiers (Figure 3). The attached computer was set-up to obtain the required load waves and torque waves for the machine. The machine was fixed to $100 \mathrm{kN}$. The computer connected to the machine (Figure 4) was used to generate the waveforms and recorded the strain gauge readings at the notch of the specimen. All readings were recorded in voltage (V) and therefore to convert these voltages to strain values calibration was done to the amplifier.

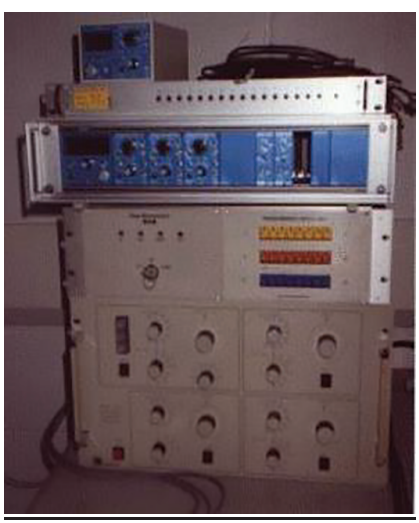

Figure 3 - Amplifiers for 3 Strain Readings and Torque

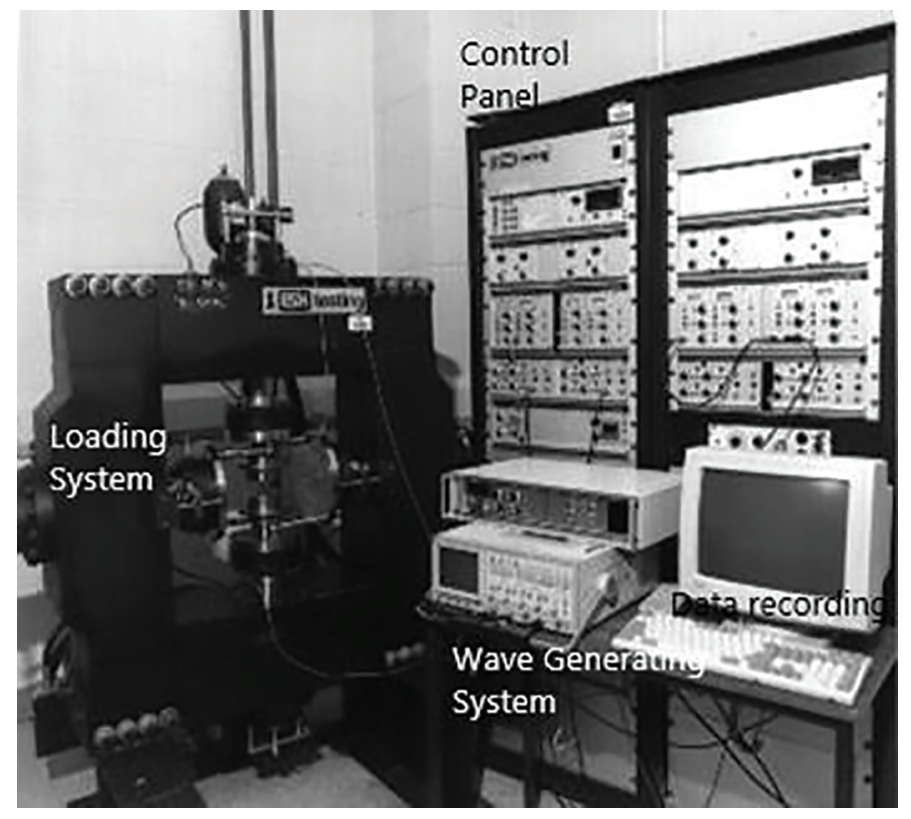

Figure 4 - Pictorial View of the Equipment

The experimental procedure consists of wave generating, loading, controlling and strain data recording systems.

\section{Selected Multiaxial Loading Paths}

Figure 5 shows the predesigned strain paths Shear strain $(\gamma)$ vs direct strain $(C)$ selected for the experiment analysis to see the hysteresis behaviour at the notch root. The axial load and torque wave paths for the ESH machine were created according to these predesigned loading paths (Figure 5).

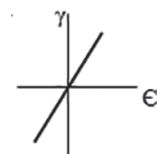

In phase

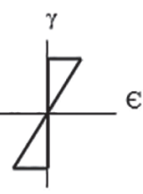

Path - C

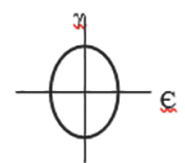

Out of phase - Path - A

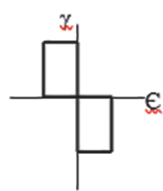

Path - D

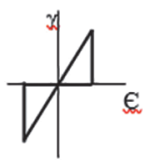

Path - B
Figure 5 - Predetermined Loading Paths - Shear Strain $(\gamma)$ vs Direct Strain $(C)$ 


\section{Results \& Analysis}

\subsection{Combined Axial - Torsion in Phase} Loading

For the experiment, different proportional (axialtorque) load sets were used. Table 2 shows the applied load and torque settings for each proportional test analysis.

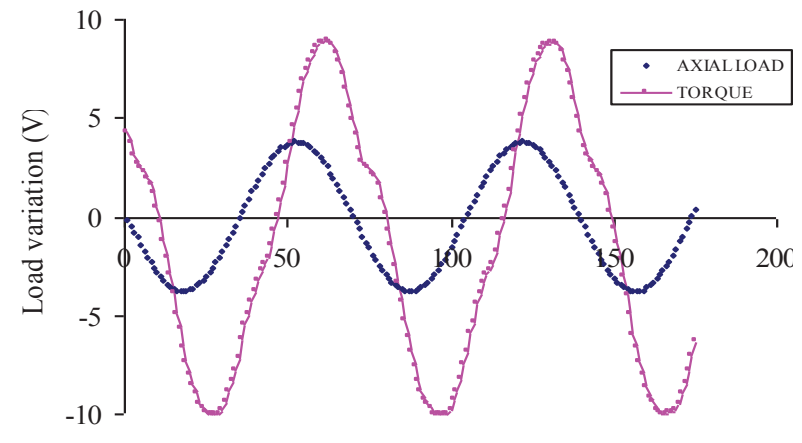

Time (Sec)

(a)

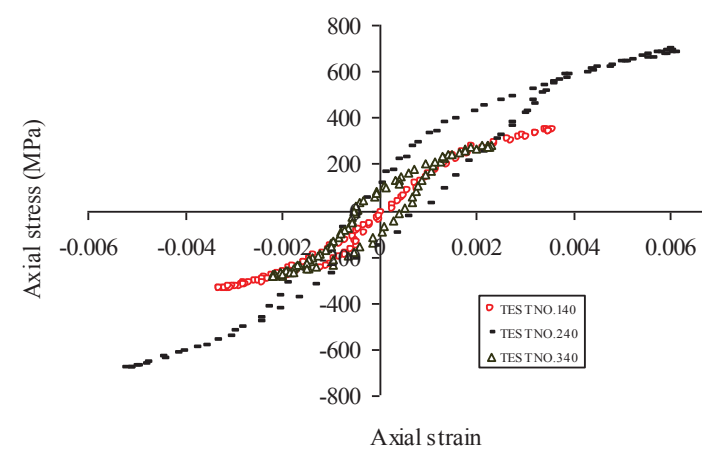

(c)
Table 2 - Applied Load and Torque Range for in Phase Loading

\begin{tabular}{|c|c|c|}
\hline Test No. & $\begin{array}{c}\text { Applied Load } \\
\text { Range }(\mathrm{kN})\end{array}$ & $\begin{array}{c}\text { Applied Torque } \\
\text { Range }(\mathrm{Nm})\end{array}$ \\
\hline 140 & 70 & 90 \\
\hline 240 & 140 & 140 \\
\hline 340 & 70 & 140 \\
\hline
\end{tabular}

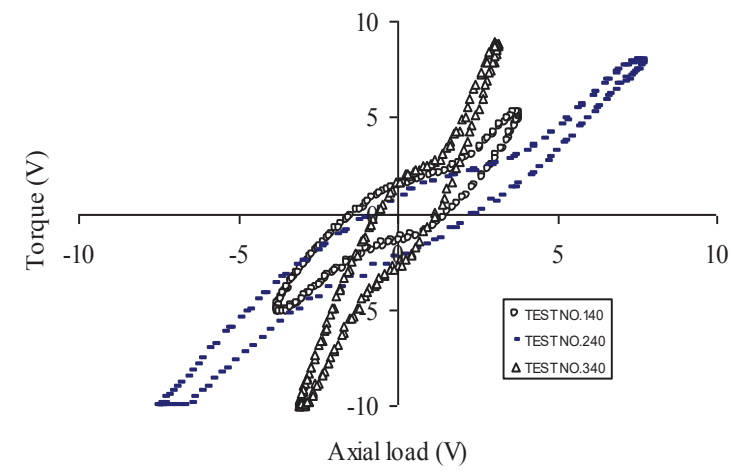

(b)

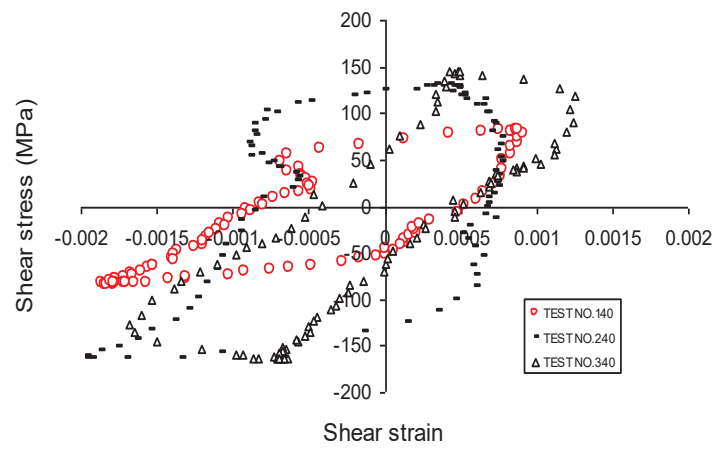

(d)

Figure 6 - (a) Recorded Axial Load and Torque Amplitudes with Time (b) Torque versus Axial Load for Different Proportional Loading Test (c) Axial Stress versus Axial Strain for Different Proportional Load Sets (d) Shear Stress versus Shear Strain for Different Proportional Load Sets

Figure 6 (c) shows the hysteresis loops for different proportional load sets given in Table 2 . As in Figure 6 (a), the path followed by the material in the real time experiment is slightly different from that of imposed in-phase sinusoidal loading path considering the torque wave pattern. However, the shape considered is acceptable for the experimental analysis. Considering Figure 6 (b), torque versus axial load should have been a straight line for the proportional loading but the machine had not taken the actual input proportional wave pattern. Hence some non-proportionality was indicated.

Input axial load wave pattern followed by the material, was same as the input wave pattern (Figure 6(a)). Therefore, the hysteresis loop, plotted for axial stress versus axial strain for inphase loading (Figure 6(c)), shows the expected shape. But the shape of the hysteresis loop (Figure 6(d)) between shear stress versus shear strain created at the notch specimen was slightly different. 
Comparing the hysteresis loops in Figure 6(c), this clearly shows that the size of the hysteresis loops increases when the applied axial load becomes higher. Therefore, the axial strain also increases with increasing amplitudes of loads. Considering the plastic area of the hysteresis loop, it is higher in Test No.340 than in Test No.140 as the applied torque of the Test No.340 is higher than that of Test No.140. That means the torque also plays a vital role in increasing the plastic energy of the axial stress-strain loop. Therefore, when there is more plasticity in Test No. 340, this can be expected to have a shorter life for higher applied load. Figure 7 shows that the size of the hysteresis loops increased when applied torques were increased. The plastic energy is higher in shear stress versus shear strain loops. Considering Table 2, Figures 6(c), and $6(\mathrm{~d})$, when the axial load and torque are low, the areas of the hysteresis loops also are low as per Test No.140. When applied axial and torsion loads are higher, the plastic area of the loops are also higher as a per Test No. 240. Considering the Test No.340, the axial load is low, but torsion load is very high and therefore the area of the shear stress versus shear strain hysteresis loop is larger than that of the loop obtained in Test No.140. Therefore, the material lifetime is expected to be shorter for a hysteresis with large plastic strain since the plastic work done on the material is believed to determine the cyclic fatigue behavior of the material.

\section{Combined Axial-Torsion Non Proportional Loading}

\subsection{Path-A $-90^{\circ}$ Out-of Phase Loads}

Table 3 shows the different load sets used for $90^{\circ}$ out-of phase tests. Figure 7(b) shows the variation of torque amplitudes versus the axial load amplitudes throughout the sinusoidal wave applied.

Table 3 - Test Details for $90^{\circ}$ Out-of Phase Loading

\begin{tabular}{|c|c|c|}
\hline Test No. & $\begin{array}{c}\text { Applied Load } \\
\text { Range }(\mathrm{kN})\end{array}$ & $\begin{array}{c}\text { Applied Torque } \\
\text { Range }(\mathrm{Nm})\end{array}$ \\
\hline 200 & 140 & 140 \\
\hline 300 & 70 & 140 \\
\hline
\end{tabular}

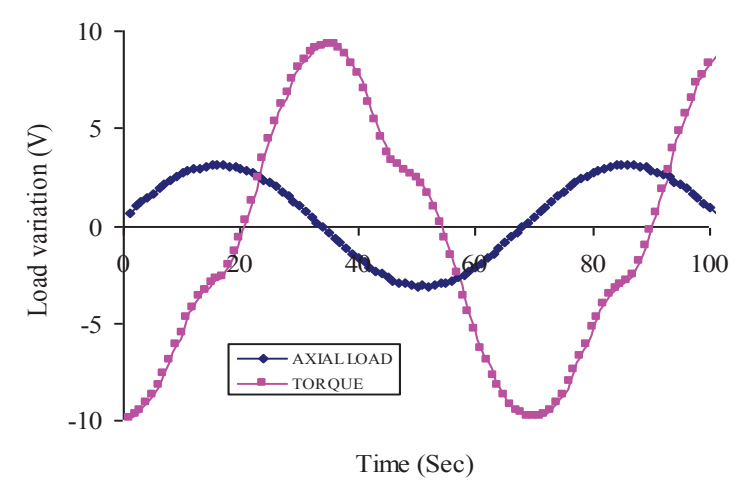

(a) (b)

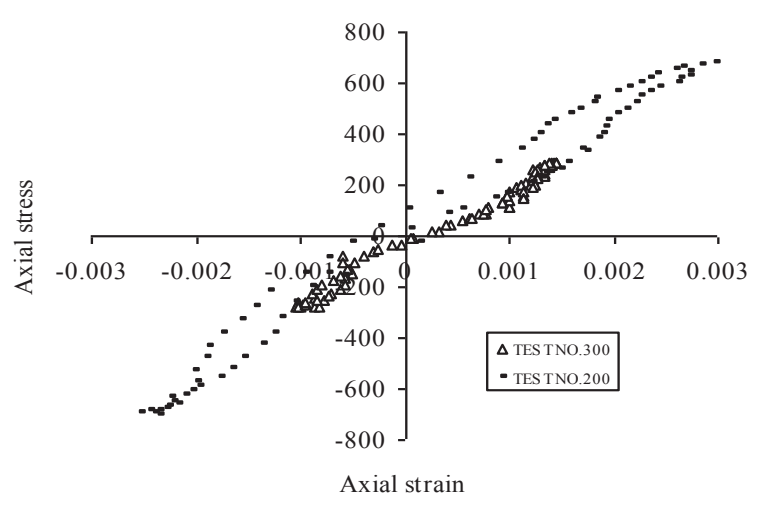

(c) (d)
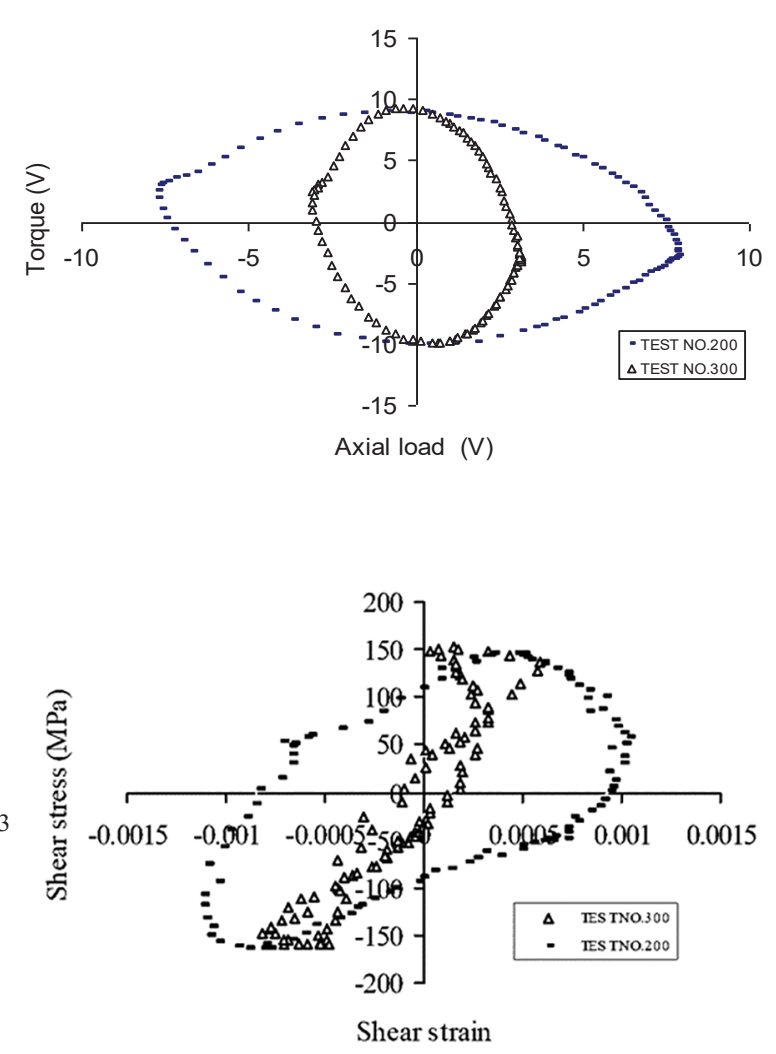

Figure 7 - (a) Recorded Axial Load and Torque Amplitudes with Time (b) Torque versus Axial Load for Different Proportional Loading Test (c) Axial Stress versus Axial Strain for Different Proportional Load Sets (d) Shear Stress versus Shear Strain for Different Load Sets for Path -A. 
For the non-proportional Path-A, two tests were performed and the hysteresis loops for axial stress/strain and shear stress/strain were compared. As in Table 3, the applied torque was same for both the tests (Test No.200 and Test No.300) and for Test No.200 the applied axial load was doubled as that was applied in Test No. 300.

As indicated in Figure 7 (c), when the amplitude of the applied load increases strain amplitude also increases. The increase in strain amplitude results in larger and longer hysteresis loops. Test No.200 has bigger plastic area than Test No.300, as the applied axial load was higher than that for Test No. 300.

As can be seen from Figure 7 (d), Test No. 200 has larger plastic area than Test No. 300 while same torque was applied. That means the axial load helps to increase the shear strain amplitude. Therefore Test No. 200 has more plastic energy than Test No.300. Also the shapes of the out-ofphase hysteresis loops were different when compared with the in-phase hysteresis loops obtained from the experiments.

\subsection{Non-Proportional Loading Path-B}

Table 4 shows the different loading cases used for non-proportional load Path-B. Figure 13 shows the variation of torque versus axial load throughout the wave.

Table 4 - Details for Path-B Loading

\begin{tabular}{|c|c|c|}
\hline $\begin{array}{l}\text { Test } \\
\text { No. }\end{array}$ & $\begin{array}{c}\text { Applied Load } \\
\text { Range }(\mathrm{kN})\end{array}$ & $\begin{array}{c}\text { Applied Torque } \\
\text { Range }(\mathrm{Nm})\end{array}$ \\
\hline 110 & 70 & 90 \\
\hline 210 & 140 & 140 \\
\hline 310 & 70 & 140 \\
\hline
\end{tabular}

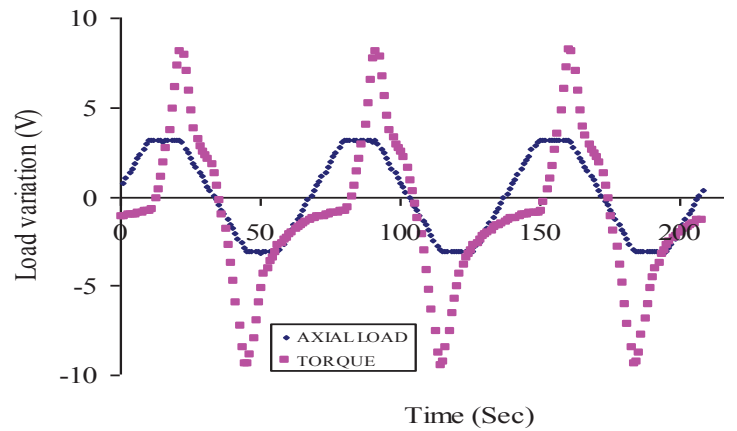

(a)

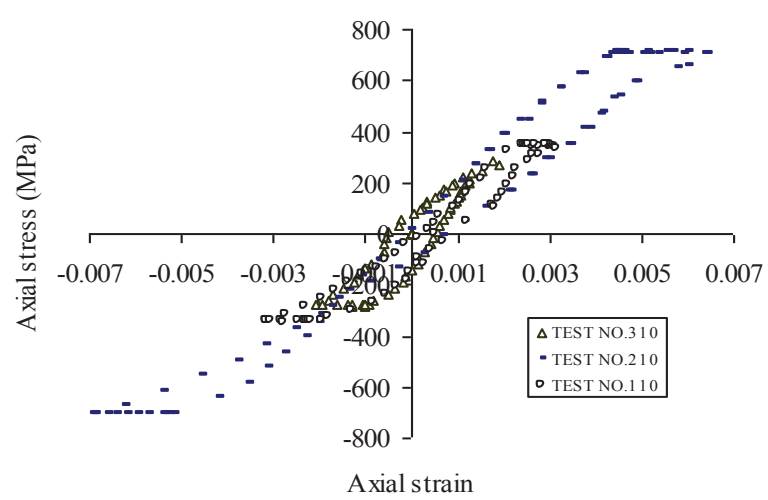

(c)

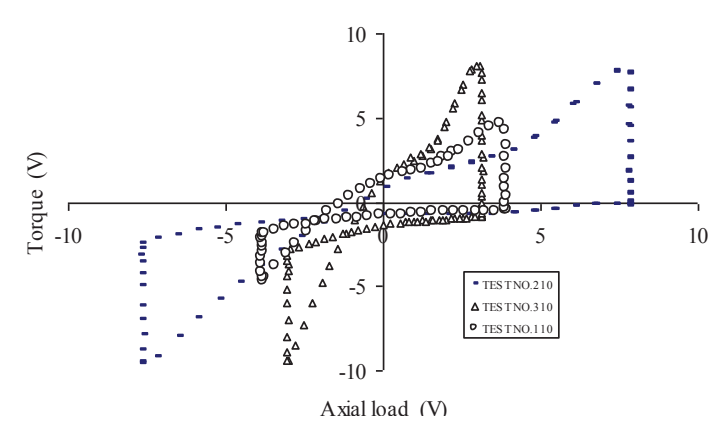

(b)

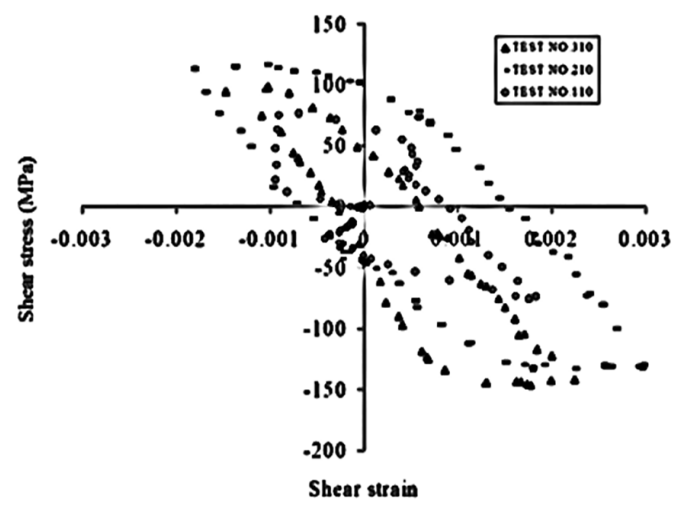

(d)

Figure 8 -(a) Recorded Axial Load and Torque Amplitudes with Time (b) Torque versus Axial Load for Different Proportional Loading Test (c) Axial Stress versus Axial Strain for Different Proportional Load Sets (d) Shear Stress versus Shear Strain for Different Load Sets for Path -B. 
The variation of applied torque versus axial load for all Path-B load cases are shown in Figure 8. The variation shown in Figure $8(\mathrm{~b})$ is same for shear strain $\gamma$ versus axial strain $\varepsilon$ for the Path-B loading. Figure 5 has indicated the desired loading path, but the path followed by the material during loading was slightly different as seen from Figure 8.

For the non-proportional Path-B, three tests were performed (Table 4). The hysteresis loops for axial stress/strain and shear stress/strain were compared. The results for axial stress/strain and shear stress/strain are shown in Figure 8 (c) and (d). Similarly, plastic area is higher in shear stress strain hysteresis loops.

As indicated in Figure 8(c), the size of the hysteresis loops increases as the applied axial load becomes higher. Considering Figure 8 (d), Test No. 210 has larger plastic area than in Test No.310 while they were applying same torque.
That means the axial load helps to increase the shear strain amplitude. Therefore Test No. 210 has more plastic energy than Test No.310. Comparing with the out-of-phase hysteresis loops (Path-A), the shapes of the hysteresis loops obtained from Path-B loadings were completely different.

\subsection{Non-Proportional Loading Path - C}

Table 5 shows the different load sets used for non-proportional load Path-C and Figure 9 shows the variation of torque against the axial load for Path-C load.

Table 5 - Test Details for Path-C Loading

\begin{tabular}{|c|c|c|}
\hline Test No. & $\begin{array}{c}\text { Applied Load } \\
\text { Range }(\mathrm{kN})\end{array}$ & $\begin{array}{c}\text { Applied Torque } \\
\text { Range }(\mathrm{Nm})\end{array}$ \\
\hline 220 & 140 & 140 \\
\hline 320 & 70 & 140 \\
\hline
\end{tabular}

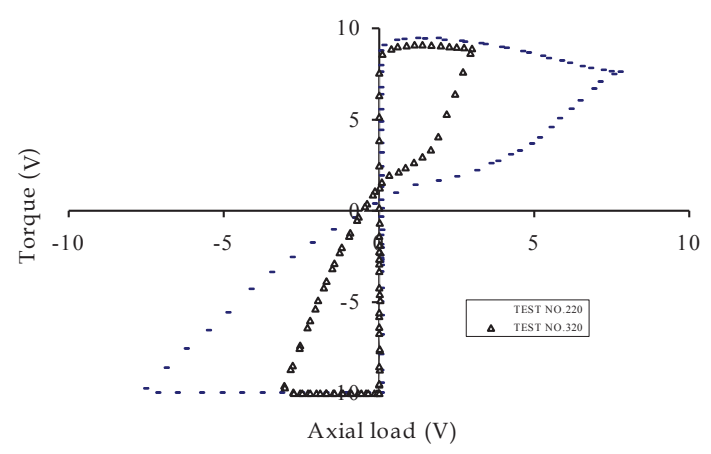

(b)

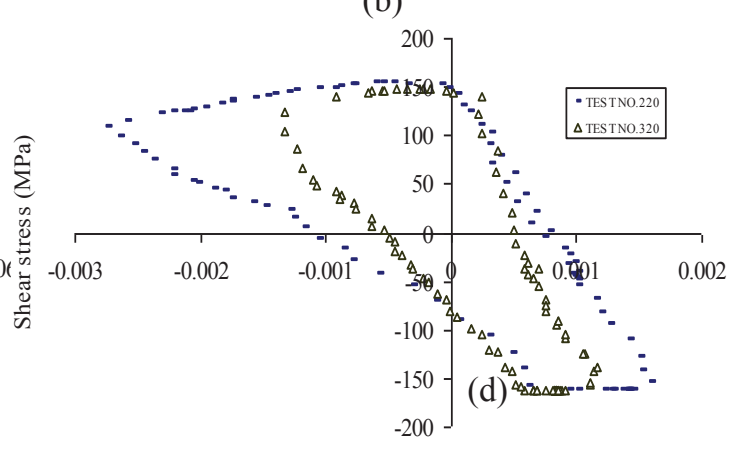

Shear strain

(d)

Figure 9 - (a) Recorded Axial Load and Torque Amplitudes with Time (b) Torque versus Axial Load for Different Proportional Loading Test (c) Axial Stress versus Axial Strain for Different Proportional Load Sets (d) Shear Stress versus Shear Strain for Different Load Sets for Path -C. 
The variations of applied torque versus axial load for two non-proportional load Path-C cases are shown in Figure 9. The shape of the variation (Figure 9) is same for shear strain $\gamma$ versus axial strain $\varepsilon$ for the Path-C loading. Figure 5 indicates the imposed loading path, but the path followed by the material in the experiment is slightly different from that imposed. But considering Figure 9(a), axial load wave pattern was similar to the imposed one, but torsion wave pattern was little different. This is an uncontrollable situation throughout the research.

For the non-proportional Path-C, two tests were performed and the hysteresis loops for axial stress/strain and shear stress/strain were compared. As in Table 5, the applied torque was same for both tests (Test No.220 and Test No.320) and for Test No.220 the applied axial load was doubled as that was applied in Test No. 320.

Therefore Test No. 220 has more plastic energy than Test No.320. Also comparing with the nonproportional loading Path-A and Path-B hysteresis loops, the shapes of the hysteresis loops obtained for Path- C were completely different.

\subsection{Non-proportional Load Path-D}

Table 6 shows the different load sets used for non-proportional load tests-Path-D.

Table 6 - Test Details for Path-D Loading

\begin{tabular}{|c|c|c|}
\hline Test No. & $\begin{array}{c}\text { Applied Load } \\
\text { Range }(\mathrm{kN})\end{array}$ & $\begin{array}{c}\text { Applied Torque } \\
\text { Range }(\mathrm{Nm})\end{array}$ \\
\hline 230 & 140 & 140 \\
\hline 330 & 70 & 140 \\
\hline
\end{tabular}

The variation of applied torque versus axial load for all Path-D load cases is shown in Figure 10(a). The shape of the variation shown in Figure 10 is expected to be same for shear strain $\gamma$ versus axial strain $\varepsilon$ for the Path-D loading. Figure 5 indicates the imposed loading path but the path followed by the material during loading was slightly different (Figures 10(c) and 10(d)). But considering the Figure 10(a), axial load wave pattern was similar to the imposed one but torsion wave pattern was little different to the previous cases. Considering Figure 10 (b), Test No. 230 has bigger plastic area than Test No. 330, although they were applying same torque.

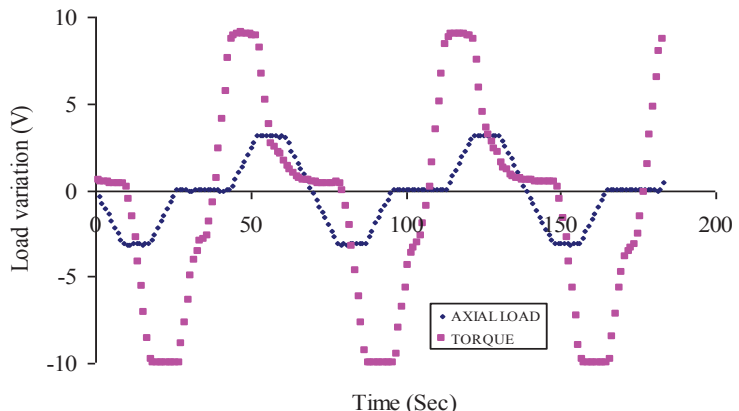

(a)

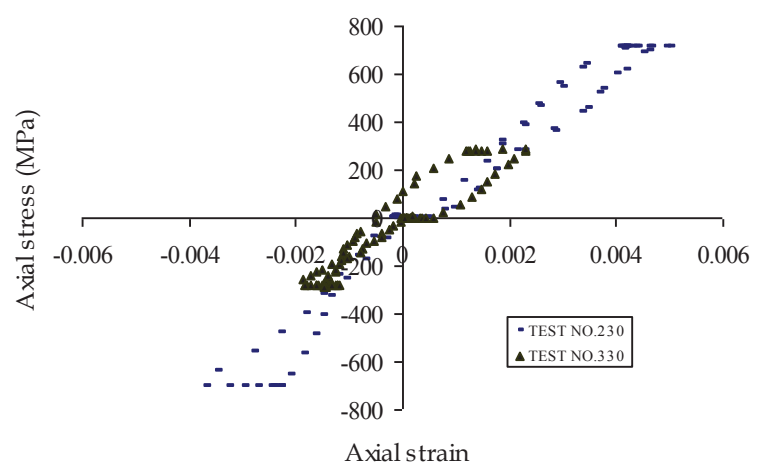

(c)

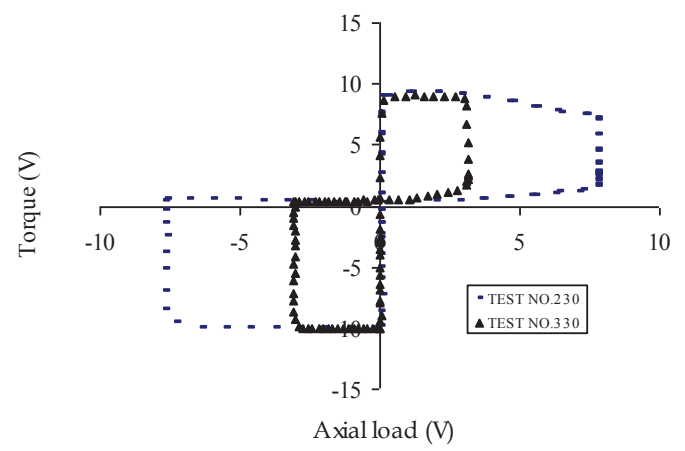

(b)

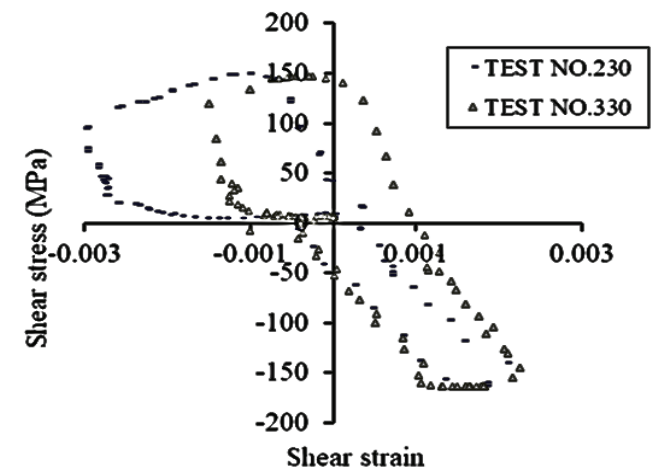

(d)

Figure 10 - (a) Recorded Axial Load and Torque Amplitudes with Time (b) Torque versus Axial Load for Different Proportional Loading Test (c) Axial Stress versus Axial Strain for Different Proportional Load Sets (d) Shear Stress versus Shear Strain for Different Load Sets for Path -D. 
Table 8 - The Axial and Shear Strain Ranges for Each Test

\begin{tabular}{|c|c|c|c|c|c|}
\hline $\begin{array}{l}\text { Test No./FEA } \\
\text { Ref No. }\end{array}$ & Loading Path & $\begin{array}{c}\text { Axial } \\
\text { Load }(\mathrm{kN})\end{array}$ & $\begin{array}{l}\text { Torque } \\
(\mathrm{Nm})\end{array}$ & $\Delta \varepsilon$ & $\Delta \gamma$ \\
\hline $\begin{array}{l}240 \\
340\end{array}$ & In-phase sine wave & $\begin{array}{c}140 \\
70\end{array}$ & $\begin{array}{l}140 \\
140\end{array}$ & $\begin{array}{l}0.0055 \\
0.0061\end{array}$ & $\begin{array}{l}0.0028 \\
0.0029\end{array}$ \\
\hline $\begin{array}{l}200 \\
300\end{array}$ & $\begin{array}{c}\text { Out of sine wave } \\
\text { Path-A }\end{array}$ & $\begin{array}{c}140 \\
70\end{array}$ & $\begin{array}{l}140 \\
140\end{array}$ & $\begin{array}{l}0.0028 \\
0.0026\end{array}$ & $\begin{array}{l}0.0022 \\
0.0014\end{array}$ \\
\hline $\begin{array}{l}210 \\
310\end{array}$ & $\begin{array}{c}\text { Non-proportional } \\
\text { Path-B }\end{array}$ & $\begin{array}{c}140 \\
70\end{array}$ & $\begin{array}{l}140 \\
140\end{array}$ & $\begin{array}{l}0.0140 \\
0.0042\end{array}$ & $\begin{array}{l}0.0049 \\
0.0027\end{array}$ \\
\hline $\begin{array}{l}220 \\
320\end{array}$ & $\begin{array}{c}\text { Non-proportional } \\
\text { Path-C }\end{array}$ & $\begin{array}{c}140 \\
70\end{array}$ & $\begin{array}{l}140 \\
140\end{array}$ & $\begin{array}{l}0.0104 \\
0.0049\end{array}$ & $\begin{array}{l}0.0043 \\
0.0025\end{array}$ \\
\hline $\begin{array}{l}230 \\
330\end{array}$ & $\begin{array}{c}\text { Non-proportional } \\
\text { Path-D }\end{array}$ & $\begin{array}{c}140 \\
70\end{array}$ & $\begin{array}{l}140 \\
140\end{array}$ & $\begin{array}{l}0.0090 \\
0.0045\end{array}$ & $\begin{array}{l}0.0055 \\
0.0035\end{array}$ \\
\hline
\end{tabular}

That means the axial load helps to increase the shear strain amplitude always. Therefore Test No. 230 has more plastic energy than Test No.330. Considering the non-proportional loading Path-A, Path-B, Path-C and Path- D, the shapes of the hysteresis loops obtained were completely different to each other.

\section{Conclusions}

Results show significant difference in hysteresis behaviour under non-proportional loading. The loops observed for out-of phase paths, Path A, B, $C$ and D in particular are of complex shape. This suggests that analytical predictions of these loops are extremely difficult. The input loading path followed by the material in the real time experiment is slightly different from that imposed loading path considering the torque wave pattern. This is due to the inaccuracies of load control system. However, the output shapes are acceptable for the experimental analysis.

The present work shows the complex loop patterns for proportional and non-proportional paths, which have not been investigated. Considerable experiment is needed to explain the shapes and they cannot be derived from simple theory like Neuber method.
The results also show that for same amplitudes of axial load/torque, different plastic strains will occur, depending on the loading path. Also the torque plays a vital role in increasing the plastic energy of the axial stress-strain loop. Therefore, fatigue life may be significantly affected by the path of loading. The results shown in Table 8 Path-B are more damaging and Path-A is least damaging in terms of fatigue life.

The study of the effect of plastic strain and loop shape on fatigue life has to be done in further studies.

\section{References}

1. Benham, P. P., Crowford, R. J., Armstrong, C. G, (1996) Mechanics of Engineering Materials, 2nd Edition, Longman Group 1996 at pp 463-544.

2. Trummer, G., Marte, C., (2015), "Rolling Contact Fatigue of Railway Wheels - A Parametric Study", International Conference on Contact Mechanics and Wear of Rail/Wheel Systems (pp. 1-8).

3. Suresh, S., (1998) Fatigue of Materials, 2nd ed., Cambridge: Cambridge University press, 1998 at pp 103-108.

4. Segerlind, L. J., Applied Finite Element Analysis, John Wiley and Sons 1976 at pp1-2. 
5. Bannantine, J., Comer, J., Handrock, Fundamentals of Metal Fatigue Analysis, Prentice Hall 1990.

6. Dover, W. D., Glinka, G., Reynolds, A. G., (1986) "Fatigue and Crack Growth in Offshore Structures", ImechE Conference Publications 1986-2.

7. Devlukia, J., Davis, J., "Fatigue Analysis of a Vehicle Structural Component under Biaxial Loading, Advanced Structural Techniques", BL Technology Limited, Gaydon Proving Ground, Lighthorne Heath, Warwickshire, C104/85, IMechE 1985 at pp 25-31.

8. Wang, Y., Pan, J., "A Plastic Fracture Mechanics Model for Characterization of Multiaxial LowCycle Fatigue", International Journal Fatigue Vol. 20.

9. Abelkis, P. R., and Hudson, C. M. Ed.s, "Design of Fatigue and Fracture Resistant Structures", Race Street 1982 at pp21.

10. Knop, M., Jones, R., Molent, L., Wang, C., (2000) "On the Glinka and Neuber Methods for Calculating Notch Tip Strains Under Cyclic Load Spectra", International Journal of Fatigue 22 June 2000, 743-755.

11. Golos, K. M., (1996) "Multiaxial Fatigue Criterion with Mean Stress Effect", International Journal Pressure Vessels and Piping.

12. Nimali T. Medagedara, "Study of Variable Amplitude in Cyclic Loading" Journal of Engineering and Technology Volume 07, No 2, September 2019, pg 1-8, ISSN 2279-2627.

13. Wheelhouse, K., "Fatigue Damage Accumulation Under Torsion and Non-Proportional Push-Pull Interruption Loading", thesis, published SHU November 2001.

14. Jayantha Das, Srinivasan M., Sivakumar, (2000) "Multiaxial Fatigue Life Prediction of a High Temperature Steam Turbine Rotor using A Critical Plane Approach", Engineering Failure Analysis 7, pp 348-358.

15. Morel, F., (2000) "A Critical Plane Approach for Life Prediction of High Cycle Fatigue Under Multiaxial Variable Amplitude Loading", International Journal of Fatigue 22, pp 101-104.

16. Miller, K. J., Brown, M. W., (1985) "Multiaxial Fatigue", A Symposium Sponsored by ASTM Committees E-9 on Fatigue and E-24 on Fracture Testing San Fransisco, CA, 1982, pp12.

17. Tipton and Nelson, Multiaxial Fatigue Life Prediction, pp 533-534.

18. Steven, M. Tipton, Drew, V., Nelson, (1996) "Advances in Multiaxial Fatigue Life Prediction for Components with Stress Concentrations", International Journal of Fatigue Vol. 19, pp 648.
19. Fuches H.O., Stephens R.I.,(1980) Metal fatigue in engineering Wiley-Interscience Publication at pp 105217.

20. Balthazar, J. C., LucivalMalcher, "A Review on the Main Approaches for Determination of the Multiaxial High Cycle Fatigue Strength" Mechanics of Solids in Brazil 2007, Brazilion Society of Mechanical Sciences and Engineering, ISBN 97885-85769-30-7.

21. Bressan, S., Razavi, J., Ogawa, F., Itoh, T., Berto F., "Multiaxial Fatigue Strength Under NonProportional Loading of Additively Manufactured Notched Components of Ti-6Al-4V"MATEC Web Conferences (2019).

22. Cernescu, A., Pullin, R., “New Research Findings on Non-Proportional Low Cycle Fatigue" MATEC Web Conferences (2019). 